\title{
Single Exposure to Antidepressants during Infancy Is Associated with Delayed Behavioral Changes in C57BL/6 Mice
}

\author{
Kazuyuki Yamada \\ Support Unit for Animal Resources Development, Research Resources Center, Brain Science Institute, RIKEN, \\ Wako, Japan \\ Email: kaz-yamada@brain.riken.jp
}

Received 15 March 2016; accepted 13 May 2016; published 16 May 2016

Copyright (C) 2016 by author and Scientific Research Publishing Inc.

This work is licensed under the Creative Commons Attribution International License (CC BY). http://creativecommons.org/licenses/by/4.0/

(c) (i) Open Access

\section{Abstract}

As serotoninergic transmission plays a crucial role in higher brain function in mammals, the disturbance of this system will likely have significant effects on emotion and cognition. Previous studies have reported that chronic treatment with Specific Serotonin Reuptake Inhibitors (SSRIs) during both late pregnancy and lactation was associated with abnormal behavior in adult rats. These data imply that disturbances in serotoninergic transmission during neurodevelopment may have negative effects on both the structure and function of the resultant adult brain. Therefore, the effect of a single exposure to an SSRI or a tricyclic antidepressant that preferentially inhibits serotonin reuptake during the pre-weaning period was examined in adult mice. An oral infusion of paroxetine $(70 \mathrm{mg} / \mathrm{kg})$, fluvoxamine $(250 \mathrm{mg} / \mathrm{kg})$, clomipramine $(180 \mathrm{mg} / \mathrm{kg})$, or saline was administered on postnatal day 14 . Starting at 11 weeks of age, mice were assessed using a comprehensive behavioral test battery. Mice treated with paroxetine demonstrated altered behavior on the open field and hole-board tasks; those treated with fluvoxamine had behavioral changes on the light-dark box, hole-board, and sucrose preference tasks, while alteration in forced swimming and cued fear behavior were noted in mice treated with clomipramine. These results suggest that even a single administration of an antidepressant could have profound effects on behavior in adulthood, although the effects might differ dependent on the specific drug that was administered.

\section{Keywords}

Antidepressants, Specific Serotonin Reuptake Inhibitors (SSRIs), Delayed Effect, Behavioral Test Battery, Mice

\section{Introduction}

Specific Serotonin Reuptake Inhibitors (SSRIs) are generally known to be effective with a relatively low risk of

How to cite this paper: Yamada, K. (2016) Single Exposure to Antidepressants during Infancy Is Associated with Delayed Behavioral Changes in C57BL/6 Mice. World Journal of Neuroscience, 6, 151-164. 
adverse events in the treatment of depression or obsessive-compulsive disorder during pregnancy and lactation [1] [2]. Furthermore, some SSRI-like substances can be easily obtained without prescription as a supplement (e.g., St John's Wort) [3]. Although the toxic effects of exposure to antidepressants in utero and during lactation have long been studied [4]-[7], it is not known whether long-term behavioral effects are exhibited in adulthood.

Some studies have reported that exposure to paroxetine in utero might lead to perinatal complications, including premature parturition [8]. Furthermore, chronic exposure to SSRIs to neonates might lead to long lasting effects on behavior. Rodent studies have shown that the sub-chronic administration of SSRIs to neonates increased immobility in the forced swimming test (Lu 10-134-C: [9]), increased locomotor activity, but decreased sexual behavior later in adulthood (citalopram: [10]) as well as a tricyclic antidepressant which preferentially but not selectively inhibits serotonin reuptake (clomipramine: [11]).

Furthermore, recent studies have suggested that behavioral changes induced by neonatal SSRI exposure might contribute to long-lasting changes in the nervous system. For instance, modification of 5-HT abundance in the brain during embryonic development in mice disrupted the precision of sensory maps formed by thalamocortical axons [12]. Similarly, an excess 5-HT in the embryonic brain affected interneuron migration [13]. In addition to these studies, data from mutant mice suggest that 5-HT itself acts as a nerve growth factor in the immature brain [14]. These results suggest the disruption of 5-HT signaling during late pregnancy or lactation may have a long-lasting effect on neural development and functioning even if the disturbance is temporally limited.

Some studies have reported that a single exposure to drugs during pregnancy and/or the neonatal period was sufficient to induce developmental and/or behavioral effects [15]-[19]. In neonates, a single exposure of domoic acid affects neurodevelopment and behavior in adulthood via glutamate receptors [16] while chlorpyrifos and carbaryl act via the cholinergic system [19]. These studies suggest that a single exposure to antidepressants, especially those that preferentially inhibit serotonin reuptake, may also disturb brain development and cause behavioral abnormalities evident in adulthood.

The present study examines three aims. The first is to assess the delayed behavioral influence of disturbances in serotoninergic transmission induced by antidepressants on a comprehensive behavioral battery. Second, we examine how a single excessive exposure of several types of antidepressant during development may influence behavior in adulthood. Finally, we compare antidepressants to characterize the unique effect of each on behavioral responding in adult mice.

\section{Materials and Methods}

\subsection{Animals}

Forty-nine (paroxetine exposure experiment), thirty-nine (fluvoxamine exposure experiment), and fifty-eight (clomipramine exposure experiment) male C57BL/6J mice were used in this study. Mice were obtained by the mating of commercially obtained male and female C57BL/6J mice (JCL, Tokyo, Japan). All mice were weaned at 4 weeks of age and then housed 3 to 4 animals of littermates per cage. At 10 weeks of age, mice were individually housed for 1 week prior to behavioral testing. The breeding and experimental rooms were air-conditioned $\left(22^{\circ} \mathrm{C}, 50 \%-60 \%\right.$ humidity) and a 12-h light-dark cycle was implemented (lights on at 0800$)$. Food and water were freely available in their home cages. All behavioral assessments except home cage activity monitoring and social interaction test were conducted during the light cycle between 1300 and 1700 . All procedures were performed in strict accordance with the guidelines of the Institute of Physical and Chemical Research (RIKEN) and were approved by the institute's Animal Investigation Committee.

\subsection{Drugs}

Paroxetine hydrochloride (LKT Laboratories, MN, USA; 70 mg/kg), fluvoxamine maleate (TRC, Ontario, Canada; $250 \mathrm{mg} / \mathrm{kg}$ ), and clomipramine hydrochloride (SIGMA, MO, USA; $180 \mathrm{mg} / \mathrm{kg}$ ) were used in this study. All drugs were dissolved at room temperature in physiological saline before behavioral testing. The selected doses were determined by previously conducted pilot experiments to determine safe and efficacious doses of each of the experimental treatments. On postnatal day 14, each animal was administered either the drug or saline orally (per os; P.O.) through a stainless-steel cannula (Muromachi-kikai, Tokyo, Japan) (10 $\mu \mathrm{l} / \mathrm{g}$ body weight).

\subsection{Procedure}

At the age of 11 weeks, behavioral testing began. A three-stage behavioral test battery was used in this study 
(Table 1). Behavioral methods of previous studies were referred to and partially modified for use in this study (see Table 1) [20]-[32]. Independent groups of mice were used in each test battery (4 - 10 mice per group). The inter-test intervals ranged between two days and two weeks, depending on the task.

Home cage activity measurement: Spontaneous home cage activity of mice was measured using a 24-channel activity measurement system (O’Hara, Tokyo, Japan). Cages were individually placed into compartments made of stainless steel in the negative breeding rack (JCL, Tokyo, Japan). A piezoelectric sensor was equipped on the ceiling of each compartment and detected mouse movement (4 to 5 times per s). Home cage activity was measured $24 \mathrm{~h}$ for one week beginning in the afternoon on the day of transferring to the behavioral laboratory and daily for the next week. After the completion of home cage activity assessment, cages and bedding materials were changed and mice were then maintained throughout behavioral screening in a micro-isolation rack (Allentown, NJ, US) identical to those used in the breeding rooms.

Open field test: A four-channel open field system was equipped in a small soundproof room $(185 \times 185 \times 225$ $\mathrm{cm}(\mathrm{H}))$. Each field was made of white plastic $(50 \times 50 \times 40(\mathrm{H}) \mathrm{cm})$ and illuminated by LEDs $(70 \mathrm{Lux}$ at the center of the field). Behavior was monitored by a charge-coupled device (CCD) camera equipped on the ceiling of the rack for the open field. During testing, the soundproof room was dark and an electronic fan was running both for ventilation and background noise $(35 \mathrm{~dB})$. In the open field test, each mouse was placed in the center of the field and allowed to move freely for $15 \mathrm{~min}$. Distance traveled (cm) and time (s) spent in the center area of the field (36\% of the center of the overall field) were adopted as indices. Data were collected every minute and analyzed using Image J OF4 (O’Hara, Tokyo, Japan).

Light-Dark $(L D)$ box test: A four-channel light-dark box system was equipped in the aforementioned soundproof room. Each light box was made of white plastic $(20 \times 20 \times 20 \mathrm{~cm}(\mathrm{H}))$ and illuminated by LEDs (250 Lux at the center of the box) with a CCD camera equipped on the ceiling. Each dark box was made of

\section{Table 1. Behavioral test batteries.}

\begin{tabular}{|c|c|c|}
\hline Behavioral task & Behavioral properties to assess & Ref. No. \\
\hline \multicolumn{3}{|l|}{ Battery 1: } \\
\hline Home cage activity & Spontaneous activity & {$[20][21]$} \\
\hline Open field test & Locomotor activity, anxiety (induced by novelty) & {$[20][21]$} \\
\hline Light-dark box test & Locomotor activity, anxiety (induced by brightness), conflict & {$[20][21]$} \\
\hline Elevated plus maze test & Locomotor activity, anxiety (induced by height), conflict & {$[20][21]$} \\
\hline Auditory startle response (and prepulse inhibition) & Hearing ability, auditory information processing & {$[20]$} \\
\hline Barnes maze test & Spatial memory & {$[22]$} \\
\hline Classical fear conditioning & Memory of fear event (both spatial and cued memory) & {$[20][21]$} \\
\hline \multicolumn{3}{|l|}{ Battery 2: } \\
\hline Hole board test & Exploration (curiosity) & {$[23]$} \\
\hline Social interaction & Affiliative behavior & {$[24]$} \\
\hline Hot plate test & Pain sensation (central) & {$[25]$} \\
\hline Tail flick test & Pain sensation (peripheral) & {$[25]$} \\
\hline Forced swimming test & Behavioral despair (depression) & {$[21]$} \\
\hline Tail suspension test & Behavioral despair (depression) & {$[21]$} \\
\hline \multicolumn{3}{|l|}{ Battery 3: } \\
\hline Elevated zero maze test & Locomotor activity, anxiety (induced by height), conflict & {$[26][29]$} \\
\hline Stair case test & Anxiety (induced by novelty), impulsiveness & {$[27]$} \\
\hline Marble burying test & Compulsiveness & {$[30][31]$} \\
\hline Sucrose preference test & Behavioral despair (depression) & {$[28]$} \\
\hline Restraint stress test (blood glucose measurement) & Stress vulnerability & {$[32]$} \\
\hline
\end{tabular}


black plastic $(20 \times 20 \times 20 \mathrm{~cm}(\mathrm{H}))$ with an infrared camera equipped on the ceiling. There was a tunnel with a sliding door in the center panel for transition between the light and dark boxes $(3 \times 5 \mathrm{~cm})$. In the LD box test, mice were individually introduced into the light box. The door to the tunnel automatically opened when the software detected the introduction of a mouse to the testing arena. Mice were then allowed to move freely in the LD box for $10 \mathrm{~min}$. Total distance traveled, percent distance traveled in the light box, percent time spent in the light box, number of the transitions between light and dark box, and the latency to first enter the dark box were measured on this task. Data were collected every minute and analyzed using Image J LD4 (O’Hara, Tokyo, Japan).

Elevated plus maze test: A single-channel elevated plus maze (closed arms: $25 \times 5 \times 15 \mathrm{~cm}(\mathrm{H})$; open arms 25 $\times 5 \times 0.3 \mathrm{~cm}(\mathrm{H})$ ) was equipped in the aforementioned soundproof room. The floor of each arm was made of white plastic while the wall of each closed arm and ridge of each open arm were made of clear plastic. Closed and open arms were arranged orthogonally $60 \mathrm{~cm}$ above the floor. Lighting during testing was 70 Lux at the center platform of the maze $(5 \times 5 \mathrm{~cm})$. In the elevated plus maze test, mice were individually placed on the center platform facing an open arm and were then allowed to move freely in the maze for 5 min. Total distance traveled, percent time spent in the open arms, and percent open arm entries were measured on this task. Data were collected every minute and analyzed using Image J EPM (O’Hara, Tokyo, Japan).

Auditory startle response and prepulse inhibition test: The auditory startle response test was conducted in a soundproof room as previously described [20]. In this test, each mouse was placed into the small cage (30 or 35 $\mathrm{mm}$ in diameter and $12 \mathrm{~cm}$ long) and set on a sensor block in the soundproof chamber $(60 \times 50 \times 67 \mathrm{~cm}(\mathrm{H}))$. A dim light was equipped on the ceiling of the soundproof chamber (10 Lux at the center of the sensor block) and 65-dB white noise was provided as background. In the auditory startle response test, mice were acclimatized to the experimental apparatus for 5 min before the experimental session began. In the first session, a $120 \mathrm{~dB}$ startle stimuli (40 ms) was presented ten times with a random inter-trial interval (10 - $20 \mathrm{~s})$. In the second session, startle response to stimuli at various intensities was assessed. Five each of 70, 75, 80, 85, 90, 95, 100, 110, and 120 $\mathrm{dB}$ white noise stimuli $(40 \mathrm{~ms})$ were presented in a quasi-random order and with a random inter-trial interval (10 - 20 s). In the prepulse inhibition (PPI) test, mice experienced five types of trials: no stimulus, startle stimulus only (120 dB, $40 \mathrm{~ms})$, prepulse $70 \mathrm{~dB}$ (20 ms, lead time $100 \mathrm{~ms})$ and pulse $120 \mathrm{~dB}$, prepulse $75 \mathrm{~dB}(20 \mathrm{~ms}$, lead time $100 \mathrm{~ms}$ ) and pulse $120 \mathrm{~dB}$, prepulse $80 \mathrm{~dB}$ (20 ms, lead time $100 \mathrm{~ms})$ and pulse $120 \mathrm{~dB}$. Each trial type was presented ten times in a quasi-random order with a random inter-trial interval (10 - $20 \mathrm{~s})$. In the final session, only a $120 \mathrm{~dB}$ startle stimuli (40 ms) was again presented ten times with a random inter-trial interval (10 - $20 \mathrm{~s})$. The total duration of the auditory startle response test was about 35 to $40 \mathrm{~min}$. After each trial, holding chambers were washed with tap water and dried using a paper towel. Apparatuses and software used for testing are commercially available (Mouse Startle; O’Hara, Tokyo, Japan).

Barnes maze test: For a spatial learning and memory task, we used the Barnes maze test. On the first day, a habituation trial was conducted. On this trial, mice were individually placed at the center of the maze and allowed to explore freely for 5 min. Following habituation, escape training commenced. During this training, mice were individually placed in the center of the maze and led to an escape hole. Mice were then encouraged to escape into one of the 12 holes on the maze (by softly pinching the animal's tail, if needed). This was repeated 5 times, changing the position of the escape hole on each trial. Maze training was conducted three times a day for four days. During training, mice were placed into a small plastic container at the center of the maze for $10 \mathrm{~s}$. The container was then opened to begin the trial. Each trial terminated when the mouse escaped into the correct hole (escape cage) or $120 \mathrm{~s}$ had elapsed. Mice were left in the escape cage for $30 \mathrm{~s}$ and then returned to their home cage. The inter-trial interval was approximately $15 \mathrm{~min}$. A probe test was conducted after the final maze training session on the fifth day. The probe test was identical to maze training, except that no escape cage was provided. The apparatuses and software used are commercially available (Image J BM; O’Hara, Tokyo, Japan).

Classical fear conditioning: The classical fear conditioning test consisted of three parts: a conditioning trial (Day 1), a context test trial (Day 2), and a cued test trial (Day 3). Fear conditioning was carried out in a clear plastic chamber equipped with a stainless steel grid floor $(34 \times 26 \times 30 \mathrm{~cm}(\mathrm{H}))$. A CCD camera was equipped on the ceiling of the chamber and was connected to a video monitor and computer. The grid floor was wired to a shock generator. White noise (65 dB) was supplied from a loudspeaker as an auditory cue (CS). The conditioning trial consisted of a 2 min exploration period followed by two CS-US pairings separated by a minute each. A US (foot shock: $0.5 \mathrm{~mA}, 2 \mathrm{~s}$ ) was administered at the end of the 30-s CS period. A context test was performed in 
the same conditioning chamber for three minutes in the absence of the white noise CS $24 \mathrm{~h}$ after the conditioning trial. Further, a cued test was performed in an alternative context with distinct cues: the testing chamber was different from the conditioning chamber in brightness (almost 0 - 1 Lux), color (white), floor structure (no grid) with bedding on the floor (alpha-dri, Shepherd, TN, USA), and shape (triangular). The cued test was conducted $24 \mathrm{~h}$ after the contextual test was completed. The cued test consisted of a 2-min exploration period (no CS) to evaluate nonspecific contextual fear followed by a 2-min CS period (no foot shock) to evaluate the cued fear. Frequency of the freezing response, characterized as immobility other than respiration and heartbeat, was measured as an index of fear memory in these mice. Data were collected and analyzed using Image J FZ2 (O'Hara, Tokyo, Japan).

Hole board test: An open field arena made of gray plastic $(50 \times 50 \times 40 \mathrm{~cm}(\mathrm{H}))$ with four equally-spaced holes ( $3 \mathrm{~cm}$ in diameter with an infrared sensor) on its floor was used (Model ST-1/WII, Muromachi-kikai, Tokyo, Japan). The field was illuminated by fluorescent light (180 Lux at the center of the field) and background noise was approximately $50 \mathrm{~dB}$. The behavior of each mouse was monitored by a CCD camera suspended about $1.5 \mathrm{~m}$ above the field. In the hole board test, mice were individually introduced into the center of the field and allowed to explore freely for $5 \mathrm{~min}$. Distance traveled (cm), latency for head dipping (s), number of head dipping, duration of head dipping (s), duration of rearing (s), and the number of rearing events were measured on this task. Data were collected and analyzed using the CompACT VAS system (Muromachi-Kikai, Tokyo, Japan).

Social interaction test (encounter method): Mice were individually put into the center of a white-colored open field $(40 \times 40 \times 30 \mathrm{~cm}(\mathrm{H}))$ with thin bedding material (alpha-dri, Shephard, TN, USA). Immediately after the introduction of the subject mouse, a target mouse (C57BL/6J, JCL, Tokyo, Japan) was introduced into the same open field arena. The duration of contact behavior was measured for $6 \mathrm{~h}$. Contact or separation of mice was expressed as a " 1 " or " 2 ," respectively, with a sampling time of $0.5 \mathrm{~s}$. If the two mice contacted one another, the software returned a value of " 1 " and if separated, returned a value of "2." Data were collected and analyzed using a computer and commercially available software (Time HC: O’Hara, Tokyo, Japan).

Hot plate and tail flick test: In the hot plate test, mice were individually placed on the plate (Model MK-350C, Muromachi-kikai, Tokyo, Japan; $52^{\circ} \mathrm{C} \pm 0.5^{\circ} \mathrm{C}$ ) enclosed by a translucent plastic wall. The time between placement and a flinch of the hind paws, licking of fore paws, and jumping was recorded manually. The maximum trial length was $90 \mathrm{~s}$ for each animal. In the tail-flick test (Model MK-330B, Muromachi-kikai, Tokyo, Japan), mice were individually restricted to the radiant heat meter, and focused heat was applied to the surface of the tail $2-3 \mathrm{~cm}$ from the tip. The latency to reflexive removal from the heat was recorded manually as the tail flick latency. The maximum testing time was $10 \mathrm{~s}$ for each animal. On each of these tests, times were recorded by two observers and the shortest latency between them on each trial was used as the response time.

Forced swimming test: Mice were individually placed in a glass cylinder $(30 \mathrm{~cm}$ high, $10 \mathrm{~cm}$ in diameter) filled $10 \mathrm{~cm}$ from the bottom with water maintained at $23^{\circ} \mathrm{C}-25^{\circ} \mathrm{C}$ for $15 \mathrm{~min}$. The duration of immobility was scored and analyzed using Image J TS (O’Hara, Tokyo, Japan).

Tail suspension test: Mice were individually hung by the tail using adhesive tape placed approximately $1.5 \mathrm{~cm}$ from the tip of the tail attached to a wire and $30 \mathrm{~cm}$ above the floor. The duration of immobility during the 5-min testing session was scored and analyzed using Image J TS (O’Hara, Tokyo, Japan).

Elevated zero maze test: A zero maze (O'Hara, Tokyo, Japan; $40 \mathrm{~cm}$ diameter, $5 \mathrm{~cm}$ width) that consisted of two enclosed areas and two open areas was hung $50 \mathrm{~cm}$ above the floor in a soundproof room. Mice were placed in the closed part of the maze and allowed to explore freely for 5 min with a luminescence of 70 Lux. Total distance (cm), percent time (sec) spent in the open areas, and percent entries into the open areas were measured as indices of performance. Data were collected and analyzed using Image J OF (O’Hara, Tokyo, Japan).

Staircase test: We used the staircase test as an additional task to assess anxiety and impulsiveness. The staircase apparatus consisted of a clear plastic enclosure (Brain Science Idea, Osaka, Japan; $10 \times 45 \times 15 \mathrm{~cm}(\mathrm{H})$ ) with five identical steps made of white plastic $(7.5 \mathrm{~cm} \times 10 \mathrm{~cm} \times 2.5 \mathrm{~cm}$ on top of each step). The box was placed in a room with constant lighting (300 Lux) and background noise (50 dB). Each animal was placed on the bottom floor of the staircase. The latency to reach the top (sec), the number of stairs climbed, and the number of rearing events was recorded during a 3-min period. Climbing was defined as each stair on which the mouse placed all four paws, and rearing was defined as each instance the mouse rose up on hind legs either on a stair or by leaning against the wall. The number of stairs descended was not taken into account.

Marble burying test: The marble burying test was conducted as previously described [30] [31]. The test was 
performed in a cage identical to the home cage with a 5-cm-thick layer of bedding material (TEK-FRESH, Edestrom, USA). Mice were habituated to fresh bedding for $30 \mathrm{~min}$ and then briefly returned to their home cage. Mice were then re-introduced into the test cage where 20 glass marbles $(1.5 \mathrm{~cm}$ in diameter) were placed evenly on the bedding, and the number of buried marbles (a marble that was at least two-thirds covered with bedding) was evaluated $30 \mathrm{~min}$ later.

Sucrose test: Mice were tested for 3 days on the 24-h version of the task, and 1 day for the 1-hr version of the task with 24-h of water deprivation. 24-h tests were a free choice between two bottles, where one bottle was filled with $3 \%$ sucrose in filtered water and the other only filtered water. To counterbalance bias for a preference to side, the position of bottles were switched every $24 \mathrm{~h}$. The consumption of the water or sucrose solution was assessed daily. After the last 24-h choice test, mice were deprived of water for $24 \mathrm{~h}$ and then the 1-h choice test between water and sucrose was conducted.

Blood glucose concentration measurement: Each mouse had their blood glucose concentration assessed three times: just before restraint stress exposure in a tight wire-mesh cage (30 min; Shinano, Tokyo, Japan), just after restraint stress exposure, and 90 min after the termination of stress exposure. Blood concentration was measured by the CareFast blood glucose sensor (Nipro, Tokyo, Japan). For each measurement, tails were cut and a small amount of blood ( $5 \mu \mathrm{l})$ was collected into a disposable sensor.

\subsection{Statistical Analysis}

Statistical analyses were conducted using the SPSSTM 19 statistical package (Japan IBM, Tokyo, Japan). Student's $t$-test was used to compare the two groups on continuous data and the Mann-Whitney's U-test was used to analyze ratio data. Repeated testing paradigms were analyzed using repeated measures ANOVA (general linear model; GLM). When Mauchly's hypothesis of sphericity was not supported, the degrees of freedom were modified using the Greenhouse-Geisser method [33]. Statistical significance was set to $p<0.05$.

\section{Results}

Results of the three stages of behavioral test battery are summarized in Table 2. A single exposure to any of the experimental drugs did not lead to many behavioral changes in adult mice, as shown in Table 2. However, drug-treated mice showed subtle but distinct behavioral changes unique to each antidepressant.

\subsection{Exposure to Paroxetine Altered Open Field Related Behaviors and Response to Restraint Stress in Adulthood}

Paroxetine-exposed mice exhibited behavioral changes in the open field and the hole-board test. In the open field test, locomotor activity of paroxetine-exposed mice was decreased relative to control mice, although this difference was not significant (Figure 1(a)). On the other hand, paroxetine-exposed mice spent significantly less time in the center area of the open field $[t(13)=3.11, p=0.008$; Figure 1(b)]. In addition, the percent time in the center of the arena for each period (60 s/bin) was calculated for time course analyses (Figure 1(c)). A repeated measures ANOVA (GLM) revealed a statistically significant main effect of drug treatment $[F(1,13)=$ 9.686, $p=0.008]$ and time bin $[F(14,182)=6.941, p<0.001]$, while the interaction between drug treatment and time bin was not significant $[F(14,182)=1.424, p=0.145]$. This result indicates altered anxiety-related behavior in paroxetine-exposed mice. However, they did not show significant differences on the other anxiety tests (the light-dark box, the elevated plus maze, and the elevated zero maze). The hole-board apparatus is a variant of the open field, but has four holes on the floor to explore. Paroxetine-exposed mice had significantly less locomotor activity in this time $[t(17)=2.45, p=0.025$ : Figure $1(\mathrm{~d})$ ) and longer latency to begin head dipping $[t$ $(17)=2.63, p=0.024$ : Figure 1(e)]. Decreased locomotion and hesitation to dip the head into the hole suggest that paroxetine-exposed mice have decreased motivation to explore the novel environment. Although changes in depression-related behaviors were expected, paroxetine-exposed mice did not demonstrate significant differences in performance on the forced swimming, tail suspension, or sucrose tests (Table 1). In spite of the absence of depressive behavior on these tasks, paroxetine-exposed mice exhibited a significantly lower blood glucose concentration immediately after the administration of restraint stress $[t(13)=2.32, p=0.037$ : Figure $1(\mathrm{f})]$. This result indicates that behavioral changes observed in paroxetine-exposed mice may in part be caused by an altered stress response to the novel environment [32]. 
Table 2. Summary of results.

\begin{tabular}{|c|c|c|c|}
\hline Behavioral task/indices & Paroxetine & Fluvoxamine & Clomipramine \\
\hline \multicolumn{4}{|l|}{ Battery 1: } \\
\hline Sample size (drug/saline) & $7 / 8$ & $7 / 10$ & $8 / 10$ \\
\hline Body weight & ns & ns & ns \\
\hline Home cage activity & ns & ns & ns \\
\hline \multicolumn{4}{|l|}{ Open field test } \\
\hline Distance traveled & ns & ns & ns \\
\hline Time center & $\downarrow$ & ns & ns \\
\hline \multicolumn{4}{|l|}{ Light-dark box test } \\
\hline Distance traveled & ns & ns & ns \\
\hline \%Distance light & ns & $\downarrow$ & ns \\
\hline \%Time light & ns & $\downarrow$ (trend) & ns \\
\hline No. of transition & ns & ns & ns \\
\hline First latency to enter dark & ns & ns & ns \\
\hline \multicolumn{4}{|l|}{ Elevated plus maze test } \\
\hline Distance traveled & ns & ns & ns \\
\hline \%Time open & ns & ns & ns \\
\hline \%Number open & ns & ns & ns \\
\hline \multicolumn{4}{|c|}{ Auditory startle response (and prepulse inhibition: PPI) } \\
\hline Startle response & ns & ns & ns \\
\hline Startle threshold & ns & ns & ns \\
\hline PPI & ns & ns & ns \\
\hline \multicolumn{4}{|l|}{ Barnes maze test } \\
\hline Distance traveled & ns & ns & ns \\
\hline Latency to enter & ns & ns & ns \\
\hline No. of error & ns & ns & ns \\
\hline Probe test & ns & ns & ns \\
\hline \multicolumn{4}{|c|}{ Classical fear conditioning (freezing) } \\
\hline Conditioning & ns & ns & ns \\
\hline Context test & ns & ns & ns \\
\hline Cued test & ns & ns & $\downarrow$ \\
\hline \multicolumn{4}{|l|}{ Battery 2: } \\
\hline Sample size (drug/saline) & $9 / 10$ & $4 / 6$ & $10 / 10$ \\
\hline \multicolumn{4}{|l|}{ Hole board test } \\
\hline Distance traveled & $\downarrow$ & $\downarrow$ & ns \\
\hline Latency for head dipping & $\uparrow$ & ns & ns \\
\hline Number of head dipping & ns & ns & ns \\
\hline Duration for head dipping & ns & ns & ns \\
\hline Duration of rearing & ns & ns & ns \\
\hline Number of rearing & ns & ns & ns \\
\hline
\end{tabular}




\begin{tabular}{|c|c|c|c|}
\hline \multicolumn{4}{|l|}{ Continued } \\
\hline Social interaction & ns & $\downarrow$ (partially) & $\uparrow$ \\
\hline Tail flick test & ns & ns & ns \\
\hline \multicolumn{4}{|l|}{ Hot plate test } \\
\hline Latency of locking & ns & ns & ns \\
\hline Latency of flinch & ns & ns & ns \\
\hline Latency of jumping & ns & ns & ns \\
\hline Forced swimming test & ns & ns & $\downarrow$ \\
\hline Tail suspension test & ns & ns & ns \\
\hline \multicolumn{4}{|l|}{ Battery 3: } \\
\hline Sample size (drug/saline) & $6 / 9$ & $6 / 6$ & $10 / 10$ \\
\hline \multicolumn{4}{|l|}{ Elevated zero maze test } \\
\hline Distance traveled & $\downarrow$ (partially) & $\uparrow$ & ns \\
\hline Latency to enter open & ns & $\downarrow$ (trend) & ns \\
\hline \%Time open & ns & $\downarrow$ (trend) & ns \\
\hline \%Number open & ns & ns & ns \\
\hline \multicolumn{4}{|l|}{ Stair case test } \\
\hline Latency to reach the top & ns & $\downarrow$ & ns \\
\hline No. of step ascend & ns & ns & ns \\
\hline No. of rearing & ns & ns & ns \\
\hline Marble burying test & ns & ns & ns \\
\hline \multicolumn{4}{|l|}{ Sucrose preference test } \\
\hline Training (consumption) & ns & ns & ns \\
\hline Preference test (vs water) & ns & $\downarrow$ & ns \\
\hline \multicolumn{4}{|c|}{ Restraint stress test (blood glucose measurement) } \\
\hline Baseline & ns & ns & ns \\
\hline Immediate after the stress & $\downarrow$ & ns & ns \\
\hline 90 min after the stress & ns & ns & ns \\
\hline
\end{tabular}

\subsection{Exposure to Fluvoxamine Altered Anxiety Behavior or Impulsiveness in Adulthood}

Contrary to the paroxetine-exposed mice, fluvoxamine-exposed mice demonstrated no differences on open field test, but exhibited some inconsistent behavioral changes among the anxiety-and depression-related tasks. In the LD box test, the percent distance traveled in the light box among fluvoxamine-exposed mice was significantly lower than that of the control mice $[U(15)=57, p=0.032$; Figure 2(a) $]$ and percent time in the light box was also decreased, although this difference was not statistically significant $[U(15)=54, p=0.064$ : Figure 2(b)]. These results suggest that fluvoxamine-exposed mice exhibited increased anxiety. Furthermore, fluvoxamineexposed mice exhibited a decreased preference to the sucrose solution in the sucrose preference test, which is often used to assess anhedonia, a common behavioral characteristic of depression $[U(8)=0, p=0.01$ : Figure 2(c)].

Although fluvoxamine-exposed mice exhibited increased anxious responding on the LD box test, they did not show any differences in the elevated plus maze test. In the elevated zero maze test, fluvoxamine-exposed mice spent proportionally less time in the open area $[U(8)=3, p=0.055$; Figure 2(e)]. However, they also had a significantly increased traveled distance $[t(8)=2.26, p=0.058$; Figure $2(d)]$. On the other hand, on the stair case test, fluvoxamine-exposed mice exhibited a significant decrease in latency to climb the stairs $[t(8)=2.99, p$ $=0.018$ : Figure 2(f)]. 
Results of Open Field Test

(a)

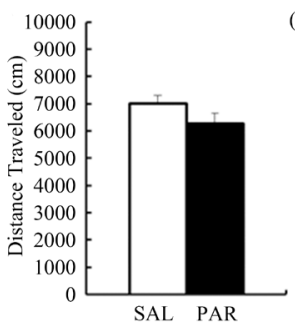

Results of Hole Board Test

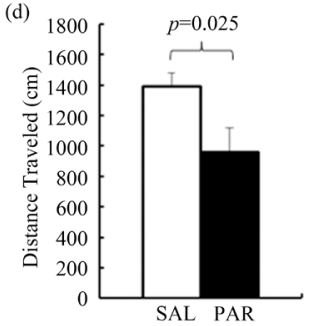

(b)
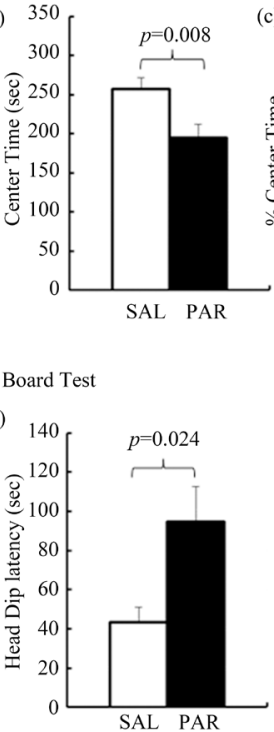

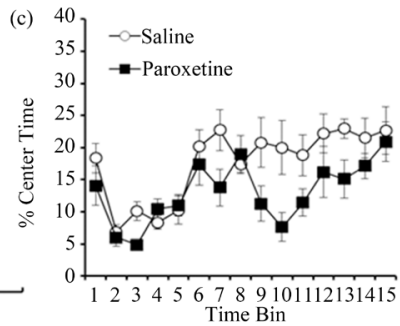

Results of Stress Test

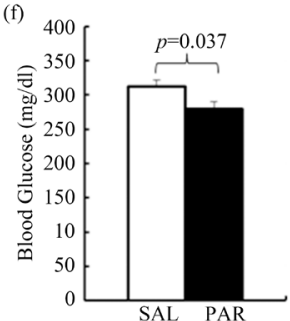

Figure 1. Comparison between behaviors of saline-and paroxetine-exposed mice. (a)-(c) Results of the open field test. Distance traveled was not statistically significant (a), but time spent in the center area (Center Time) was significantly reduced in paroxetine-exposed mice (b). A time course analysis revealed a significant decrease of the proportion of time spent in the center among paroxetine-exposed mice (c). d, e: Results of the hole-board test. Contrary to the open field test, distance traveled was significantly reduced in paroxetine-exposed mice (d) and time to the first head dip (head dip latency) was significantly increased in paroxetine-exposed mice (e). (f) Results of blood glucose concentration measurement. Paroxetine-exposed mice had significantly lower blood glucose concentrations than saline-exposed mice after the 30-min restraint stress. Data represent mean + standard error of the mean (SEM). SAL: saline-treated mice, PAR: paroxetine-exposed mice.

\subsection{Exposure to Clomipramine Impaired Cued Fear Memory}

In the forced swimming test, mice exposed to clomipramine showed a significant main effect of drug treatment $[F(1,18)=9.151, p=0.007]$ and time bin $[F(5.377,96.784)=37.989, p<0.001]$, but the interaction between drug treatment and time bin was not significant $[F(5.377,96.784)=0.916, p=0.479]$. Mean immobility rate was also statistically significant [whole test: $U(18)=13, p=0.005$, data not shown; bin 1 to $5: U(18)=16, p=$ 0.01 , Figure 3(a) inset]. In addition, clomipramine-exposed mice exhibited an increased number of social interactions [Figure 3(b): $U(18)=77, p=0.041$ ]. These results suggest that a single exposure to clomipramine during development might not lead to changes in depressive responding.

Furthermore, clomipramine-exposed mice exhibited a slight but statistically significant impairment in cued memory on the fear conditioning test (Figure 3(c)). A repeated measures ANOVA (GLM) revealed a statistically significant main effect of test condition [no_CS vs. CS: $F(1,16)=243.05, p<0.001$ ] and interaction between test condition and drug treatment $[F(1,16)=8.460, p=0.01]$. However, the main effect of drug treatment was not significant $[F(1,16)=2.805, p=0.113]$. As the interaction between test condition and drug treatment was significant, the simple main effect was analyzed. The effect of drug treatment in the no_CS condition was not statistically significant $[F(1,16)=0.37, \mathrm{p}=0.551]$ but was significant in the CS condition $[F(1$, $16)=8.45, p=0.01]$. Clomipramine-exposed mice did not demonstrate any changes in the auditory startle response and its prepulse inhibition, therefore the decreased freezing response exhibited on the cued fear test is not likely caused by a difficulty with hearing.

\section{Discussion}

In the present study, we demonstrated that among infant mice, a single exposure to antidepressants might affect 

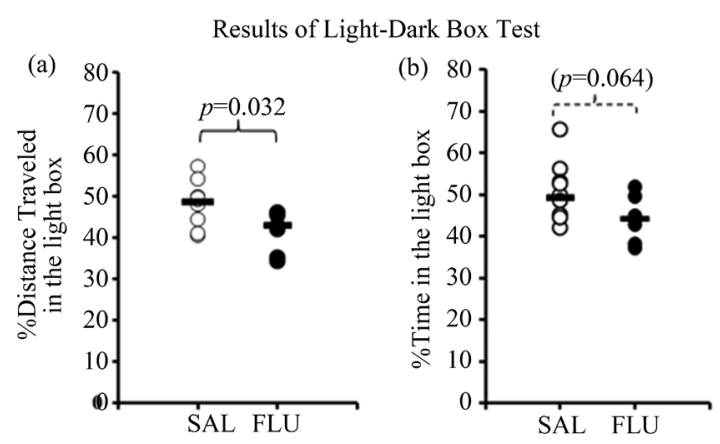

Results of Sucrose Preference Test
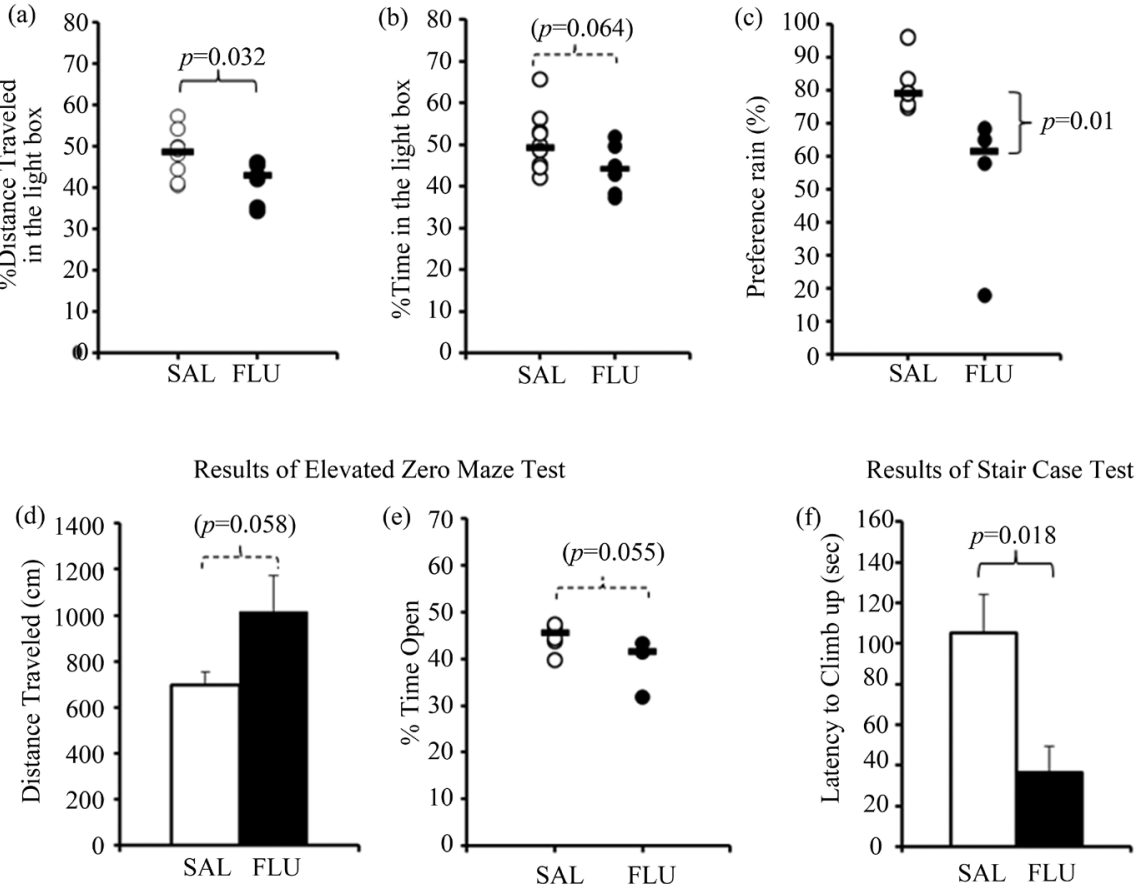

Figure 2. Behavioral comparison of saline-and fluvoxamine-exposed mice. (a) (b) Results of the light-dark box test. The ratio of the distance traveled in the light box was significantly lower in fluvoxamine-exposed relative to saline-exposed mice (a). Although the percent time in the light box was decreased among fluvoxamine-exposed mice, the difference was not statistically significant (b). (c) Results of the sucrose preference test after 24 $\mathrm{h}$ of water deprivation. Preference for sucrose was greatly reduced in fluvoxamine-exposed mice. (d) (e) Results of the elevated zero maze test. Contrary to the light-dark box test, fluvoxamine-exposed mice displayed an increased distance traveled (d) and a decreased percent of time in the open area (e), although this was not statistically significant. F: Results of the stair-case test. Time required to climb up the stairs was decreased in fluvoxamine-exposed relative to saline-exposed mice. Data represent mean + standard error of the mean (SEM) (d) (f). Bars represent median (a)-(c), (e). SAL: saline-treated mice, FLU: fluvoxamine-exposed mice.

their emotional behavior in adulthood. Paroxetine-exposed mice had less reactivity to the novel environment (e.g., decreased time spent in the center of the open field arena, decreased distance traveled, increased head dip latency on the hole board test, and decreased response to the restraint stress; Figure 1). On the other hand, fluvoxamine-exposed mice displayed less consistent behavioral responding (e.g., increased anxiety response on the LD box test, depressive responding on the sucrose test, but impulsive responding on the stair case test; Figure 2). The discrepancies of anxiety-related behaviors among the light-dark box test, the elevated zero maze test, and the stair case test suggest that fluvoxamine exposure during development may affect the serotoninergic functioning that mediates anxiety responding in adult animals. Clomipramine-exposed mice exhibited a decreased tendency for depressive behaviors, contrary to previous findings (decreased immobility in the forced swimming test; Figure 3(a)) [9]. Furthermore, these animals exhibited an emotional memory deficit in classical fear conditioning (Figure 3(c)). These results suggest that even a transient disturbance to 5-HT neural transmission has long-lasting effects on neuronal development and function. Results of the present study parallel those of previous studies using a rat model [9]-[11] [34]. Furthermore, these results suggest that each drug affects the fine tuning of serotoninergic neurotransmission and neural development differentially.

Effects of exposure to antidepressants in utero and during lactation have been studied in both humans and animals. Clinical studies revealed that exposure to antidepressants during pregnancy may cause physical problems in the newborn (e.g. hypertension, low body weight) [35] [36]. During lactation, SSRIs can be transmitted to infants via breast milk [37] [38]. Although a few studies have reported significant adverse effects on children 
(a)

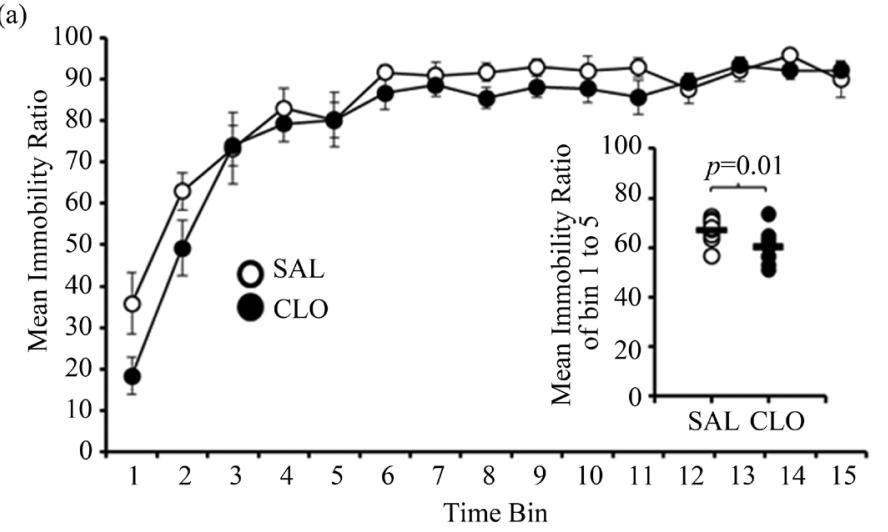

Results of

Social Interaction Test

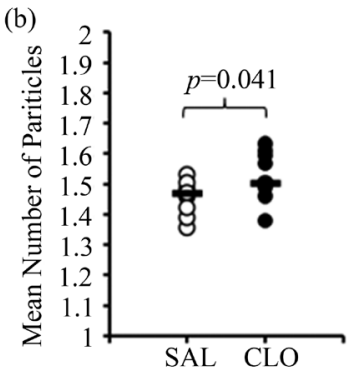

Results of

Fear Conditioning Test

(c)

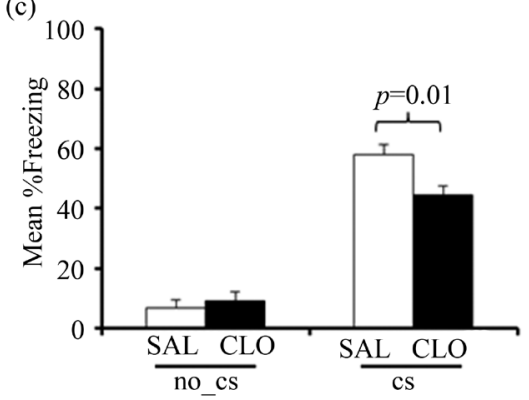

Figure 3. Behavioral comparison of saline-and clomipramine-exposed mice. (a) Results of the forced swimming test. Clomipramine-exposed mice showed a slight decrease in the ratio of time spent immobile. Inset shows the mean immobility ratio of bins 1 to 5 . Each time bin represents one minute. (b) Results of the social interaction test. Clomipramine-exposed mice exhibited more affiliative behavior than saline-exposed mice. (c) Results of the classical fear conditioning test. There were no differences during the no_CS period, although the freezing rate of clomipramine-exposed mice was significantly reduced in the CS period. Data represent mean + standard error of the mean (SEM) (main graph of (a), (c)). Bars represent median (inset of (a), (b)). SAL: saline-treated mice, CLO: clomipramine-exposed mice.

after exposure to antidepressants via breast milk, most studies have focused on the pharmacokinetics of antidepressants in breast-feeding. Thus, the long-term effects of exposure to antidepressants during neurodevelopment on behaviors in adulthood are still unknown [39] [40]. Many studies have reported long-lasting and/or late onset effects of exposure during development to antidepressants among animals (i.e., neonatal antidepressant exposure syndrome: NADES) [40]-[42].

NADES posits two fundamental questions in this field of research. The first is whether antidepressant exposure in utero affects neurodevelopment and behavior. The second is whether functional changes caused by antidepressant exposure in utero or during lactation are associated with structural changes. Animal research thus far strongly suggests that antidepressant exposure in utero may affect neurodevelopment and subsequent adult behavior. However, few longitudinal clinical studies of this nature exist [43] [44]. It is necessary to elucidate whether the discrepancy in findings is influenced by differences in species or research methodology. Mice lacking the serotonin transporter (SERT KO) exhibited abnormal social behavior [45] and anxiety-related behaviors [46]. Furthermore, the number and firing rate of serotoninergic neurons in the Dorsal Raphe Nucleus (DRN) were significantly diminished in SERT KO mice [47]. These results indicate that the disturbance of serotoninergic neurotransmission during development may have long-term functional effects on structural and physiologi- 
cal changes in the brain. In addition, some studies have reported that an excess of 5-HT during neurodevelopment may lead to behavioral and cellular changes associated with the paraventricular and central nuclei of amygdala, which are known to be integral in emotional behaviors exhibited by rats and mice [48] [50].

In contrast to previous studies that chronically exposed animals to drugs, this study used a single excessive exposure to a variety of antidepressants. Therefore, the mechanisms that mediate behavioral change in this study may differ from those of previous studies because of this methodological discrepancy. However, a single disturbance in glutamatergic [16] and cholinergic neurotransmission [18] during brain development resulted in both structural and/or behavioral changes in adulthood. Thus, any exposure to antidepressants during this sensitive period of brain development may exert a meaningful influence. Further structural, biochemical, and behavioral studies using antidepressants to characterize this sensitive period will be useful in the understanding of the neuronal development and the pathogenesis of mental disorders.

\section{Acknowledgements}

I would like to thank Drs. Kanno J. and Kitajima S. at National Institute of Health Sciences and Professor Tanemura K. at Tohoku University for inviting me to work on this research project in developmental and behavioral toxicology. I would also like to thank Ms. Homma C. for her technical assistance. This study was in part supported by Health Sciences Research Grants from the Ministry of Health, Labour, and Welfare, Japan (FY 2008-2010).

\section{References}

[1] Wisner, K.L., Zarin, D.A., Holmboe, E.S., Applebaum, P.S., Gelenberg, A.J., Leonard, H.L. and Frank, E. (2000) Risk-Benefit Decision Making for Treatment of Depression during Pregnancy. American Journal of Psychiatry, 157, 1933-1940. http://dx.doi.org/10.1176/appi.ajp.157.12.1933

[2] Cohen, L.S., Nonacs, R., Viguera, A.C. and Reminick, A. (2004) Diagnosis and Treatment of Depression during Pregnancy. CNS Spectrums, 9, 209-216.

[3] Saeed, A., Bloch, R.M. and Antonacci, D.J. (2007) Herbal and Dietary Supplements for Treatment of Anxiety Disorders. American Family Physician, 76, 549-556.

[4] Previti, G., Pawlby, S., Chowdhury, S., Aguglia, E. and Pariante, C.M. (2014) Neurodevelopmental Outcome for Offspring of Women Treated for Antenatal Depression: A Systematic Review. Archives of Women's Mental Health, 17, 471-483. http://dx.doi.org/10.1007/s00737-014-0457-0

[5] Yonkers, K.A., Blackwell, K.A., Glover, J. and Forray, A. (2014) Antidepressant Use in Pregnant and Postpartum Women. Annual Review of Clinical Psychology, 10, 369-392. http://dx.doi.org/10.1146/annurev-clinpsy-032813-153626

[6] Kiryanova, V., McAllister, B.B. and Dyck, R.H. (2013) Long-Term Outcomes of Developmental Exposure to Fluoxetine: A Review of the Animal Literature. Developmental Neuroscience, 35, 437-449.

[7] Byatt, N., Deligiannidis, K.M. and Freeman, M.P. (2013) Antidepressant Use in Pregnancy: A Critical Review Focused on Risks and Controversies. Acta Psychiatrica Scandinavica, 127, 94-114. http://dx.doi.org/10.1111/acps.12042

[8] Gentile, S. (2007) Serotonin Reuptake Inhibitor-Induced Perinatal Complications. Pediatric Drugs, 9, 97-106. http://dx.doi.org/10.2165/00148581-200709020-00003

[9] Hansen, H.H., Sanchez, C. and Meier, E. (1997) Neonatal Administration of the Selective Serotonin Reuptake Inhibitor Lu 10-134-C Increases Forced Swimming-Induced Immobility in Adult Rats: A Putative Animal Model of Depression? JPET, 283, 1333-1341.

[10] Maciag, D., Simpson, K.L., Coppinger, D., Lu, Y., Wang, Y., Lin, R.C. and Paul, I.A. (2006) Neonatal Antidepressant Exposure Has Lasting Effects on Behavior and Serotonin Circuitry. Neuropharmacology, 31, 47-57.

[11] Velazquez-Moctezuma, J. and Diaz Ruiz, O. (1992) Neonatal Treatment with Clomipramine Increased Immobility in the Forced Swim Test: An Attribute of Animal Models of Depression. Pharmacology Biochemistry and Behavior, 42, 737-739. http://dx.doi.org/10.1016/0091-3057(92)90022-8

[12] Bonnin, A., Torii, M., Wang, L., Rakic, P. and Levitt, P. (2007) Serotonin Modulates the Response of Embryonic Thalamocortical Axons to Netrin-1. Nature Neuroscience, 10, 588-597. http://dx.doi.org/10.1038/nn1896

[13] Riccio, O., Potter, G., Walzer, C., Vallet, P., Szabo, G., Vutskits, L., Kiss, J.Z. and Dayer, A.G. (2009) Excess of Serotonin Affects Embryonic Interneuron Migration through Activation of the Serotonin Receptor 6. Molecular Psychiatry, 14, 280-290. http://dx.doi.org/10.1038/mp.2008.89

[14] Nakatani, J., Tamada, K., Hatanaka, F., Ise, S., Ohta, H., Inoue, K., Tomonaga, S., Watanabe, Y., Chung, Y.J., Baner- 
jee, R., Iwamoto, K., Kato, T., Okazawa, M., Yamauchi, K., Tanda, K., Takeo, K., Miyakawa, T., Bradley, A. and Takumi, T. (2009) Abnormal Behavior in a Chromosome-Engineered Mouse Model for Human 15q11-13 Duplication Seen in Autism. Cell, 137, 1235-1246. http://dx.doi.org/10.1016/j.cell.2009.04.024

[15] Faqi, A.S., Dalsenter, P.R., Merker, H.J. and Chahoud, I. (1998) Effects on Developmental Landmarks and Reproductive Capability of 3,3',4,4'-Tetrachlorobiphenyl and 3,3',4,4',5-Pentachlorobiphenyl in Offspring of Rats Exposed during Pregnancy. Human \& Experimental Toxicology, 17, 365-372. http://dx.doi.org/10.1191/096032798678908954

[16] Tanemura, K., Igarashi, K., Matsugami, T.-R, Aisaki, K.-I., Kitajima, S. and Kanno, J. (2009) Intrauterine Environment-Genome Interaction and Children's Development (2): Brain Structure Impairment and Behavioral Disturbance Induced in Male Mice Offspring by a Single Intraperitoneal Administration of Domoic Acid (DA) to Their Dams. The Journal of Toxicological Sciences, 34, SP279-SP286. http://dx.doi.org/10.2131/jts.34.SP279

[17] Berretti, R., Santoru, F., Locci, A., Sogliano, C., Calza, A., Choleris, E., Porcu, P. and Concas, A. (2014) Neonatal Exposure to Estradiol Decreases Hypothalamic Allopregnanolone Concentrations and Alters Agonistic and Sexual but not Affective Behavior in Adult Female Rats. Hormones and Behavior, 65, 142-153. http://dx.doi.org/10.1016/j.yhbeh.2013.12.009

[18] Lee, I., Eriksson, P., Fredriksson, A., Buratovic, S. and Viberg, H. (2015) Developmental Neurotoxic Effects of Two Pesticides: Behavior and Biomolecular Studies on Chlorpyrifos and Carbaryl. Toxicology and Applied Pharmacology, 288, 429-438. http://dx.doi.org/10.1016/j.taap.2015.08.014

[19] Lee, I., Eriksson, P., Fredriksson, A., Buratovic, S. and Viberg, H. (2015) Developmental Neurotoxic Effects of Two Pesticides: Behavior and Neuroprotein Studies on Endosulfan and Cypermethrin. Toxicology, 335, 1-10. http://dx.doi.org/10.1016/j.tox.2015.06.010

[20] Sakatani, S., Yamada, K., Homma, C., Munesue, S., Yamamoto, Y., Yamamoto, H. and Hirase, H. (2009) Deletion of RAGE Causes Hyperactivity and Increased Sensitivity to Auditory Stimuli in Mice. PLoS ONE, 4, e8309. http://dx.doi.org/10.1371/journal.pone.0008309

[21] Katayama, K., Yamada, K., Ornthanalai, V.G., Ota, M., Murphy, N.P. and Aruga, J. (2010) Slitrk1-Deficient Mice Display Elevated Anxiety-Like Behavior and Noradrenergic Abnormalities. Molecular Psychiatry, 15, 177-184. http://dx.doi.org/10.1038/mp.2008.97

[22] Miyakawa, T., Yared, E., Pak, J.H., Huang, F.L., Huang, K.-P. and Crawley, J.N. (2001) Neurogranin Null Mutant Mice Display Performance Deficits on Spatial Learning Tasks with Anxiety Related Components. Hippocampus, 11, 763-775. http://dx.doi.org/10.1002/hipo.1092

[23] Kamei, J., Ohsawa, M., Tsuji, M., Takeda, H. and Matsuyama, T. (2001) Modification of the Effects of Benzodiazepines on the Exploratory Behaviors of Mice on a Hole-Board by Diabetes. The Japanese Journal of Pharmacology, 86, 47-54. http://dx.doi.org/10.1254/jjp.86.47

[24] Miyakawa, T., Leiter, L.M., Gerber, D.J., Gainetdinov, R.R., Sotnikova, T.D., Zeng, H., Caron, M.G. and Tonegawa, S. (2003) Conditioned Calcineurin Knockout Mice Exhibit Multiple Abnormal Behaviors Related to Schizophrenia. Proceedings of the National Academy of Sciences of the United States of America, 100, 8987-8992. www.pnas.org/cgi/doi/10.1073/pnas.1432926100 http://dx.doi.org/10.1073/pnas.1432926100

[25] Koide, T., Moriwaki, K., Ikeda, K., Niki, H. and Shiroishi, T. (2000) Multi-Phenotype Behavioral Characterization of Inbred Strains Derived from Wild Stocks of Mus musculus. Mammalian Genome, 11, 664-670. http://dx.doi.org/10.1007/s003350010129

[26] Uchida, S., Kitamoto, A., Umeeda, H., Nakagawa, N., Masushige, S. and Kida, S. (2005) Chronic Reduction in Dietary Tryptophan Leads to Changes in the Emotional Response to Stress in Mice. Journal of Nutritional Science and Vitaminology, 51, 175-181. http://dx.doi.org/10.3177/jnsv.51.175

[27] Ago, Y., Takahashi, K., Nakamura, S., Hashimoto, H., Baba, A. and Matsuda, T. (2007) Anxiety-Like and Exploratory Behaviors of Isolation-Reared Mice in the Staircase Test. Journal of Pharmacological Sciences, 104, 153-158. http://dx.doi.org/10.1254/jphs.FP0070325

[28] Strekalova, T., Spanagel, R., Bartsch, D., Henn, F.A. and Gass, P. (2004) Stress-Induced Anhedonia in Mice Is Associated with Deficits in Forced Swimming and Exploration. Neuropsychopharmacology, 29, 2007-2017. http://dx.doi.org/10.1038/sj.npp.1300532

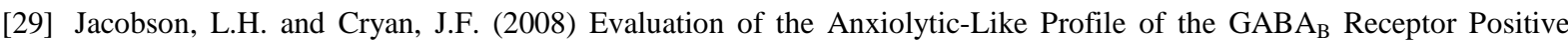
Modulator CGP7930 in Rodents. Neuropharmacology, 54, 854-862. http://dx.doi.org/10.1016/j.neuropharm.2008.01.004

[30] Yamada, K., Wada, E., Yamano, M., Sun, Y.-J., Ohara-Imaizumi, M., Nagamatsu, S. and Wada, K. (2002) Decreased Marble Burying Behavior in Female Mice Lacking Neuromedin-B Receptor (NMB-R) Implies the Involvement of NMB/NMB-R in 5-HT Neuron Function. Brain Research, 942, 71-78. http://dx.doi.org/10.1016/S0006-8993(02)02696-3 
[31] Homma, C. and Yamada, K. (2009) Physical Properties of Bedding Materials Determine the Marble Burying Behavior of Mice (C57BL/6J). The Open Behavioral Science Journal, 3, 34-39. http://dx.doi.org/10.2174/1874230000903010034

[32] Kanuma, E., Watanabe, M., Tomiyama-Miyaji, C., Inoue, M., Kuwano, Y., Ren, H. and Abo, T. (2009) Association of Glucocorticoid with Stress-Induced Modulation of Body Temperature, Blood Glucose and Innate Immunity. Psychoneuroendocrinology, 34, 1459-1468. http://dx.doi.org/10.1016/j.psyneuen.2009.04.021

[33] Chino, N. (1994) A Critical Review on and around Sphericity Tests. Bulletin of Faculty of Fumanities of Aichi Gakuin University, 24, 103-119.

[34] Rodriguez Echandia, E.L., Foscolo, M.R. and Gonzalez, A. (1988) Effect of Perinatal Exposure to Therapeutic Doses of Chlomipramine on Grooming Behavior in the Adult Rata. Annals of the New York Academy of Sciences, 525, 80-88. http://dx.doi.org/10.1111/j.1749-6632.1988.tb38597.x

[35] Elfolk, M. and Malm, H. (2010) Risks Associated with in Utero and Lactation Exposure to Selective Serotonin Reuptake Inhibitors (SSRIs). Reproductive Toxicology, 30, 249-260. http://dx.doi.org/10.1016/j.reprotox.2010.04.015

[36] Simoncelli, M., Martin, B.-Z. and Berard, A. (2010) Antidepressant Use during Pregnancy: A Critical Systematic Review of the Literature. Current Drug Safety, 5, 153-170. http://dx.doi.org/10.2174/157488610790936114

[37] Yoshida, K., Smith, B., Craggs, M. and Kumar, R.C. (1998) Fluoxetine in Breast-Milk and Developmental Outcome of Breast-Fed Infants. The British Journal of Psychiatry, 172, 175-178. http://dx.doi.org/10.1192/bjp.172.2.175

[38] Stowe, Z.N., Cohen, L.S., Hostetter, A., Ritchi, J.C., Owens, M.J. and Nemeroff, C.B. (2000) Paroxetine in Human Breast Milk and Nursing Infants. The American Journal of Psychiatry, 157, 185-189. http://dx.doi.org/10.1176/appi.ajp.157.2.185

[39] Orsolini, L. and Bellantuono, C. (2015) Serotonin Reuptake Inhibitors and Breastfeeding: A Systematic Review. Human Psychopharmacology: Clinical and Experimental, 30, 4-20. http://dx.doi.org/10.1002/hup.2451

[40] Gentile, S. (2015) Managing Antidepressant Treatment in Pregnancy and Puerperium. Careful with That Axe, Eugene. Expert Opinion on Drug Safety, 14, 1011-1014. http://dx.doi.org/10.1517/14740338.2015.1037273

[41] Mirmiran, M., Van De Poll, N.E., Corner, M.A., Van Oyen, H.G. and Bour, H.L. (1981) Suppression of Active Sleep by Chronic Treatment with Chlorimipramine during Early Postnatal Development: Effects upon Adult Sleep and Behavior in the Rat. Brain Research, 204, 129-146. http://dx.doi.org/10.1016/0006-8993(81)90657-0

[42] Hilakivi, L.A., Sinclair, J.D. and Hilakivi, I.T. (1984) Effects of Neonatal Treatment with Clomipramine on Adult Ethanol Related Behavior in the Rat. Developmental Brain Research, 15, 129-132. http://dx.doi.org/10.1016/0165-3806(84)90148-2

[43] Hilakivi, L.A. and Hilakivi, I. (1987) Increased Adult Behavioral “Despair” in Rats Neonatally Exposed to Desipramine or Zimeldine: An Animal Model of Depression? Pharmacology Biochemistry and Behavior, 28, 367-369. http://dx.doi.org/10.1016/0091-3057(87)90454-0

[44] Gentile, S. and Galbally, M. (2011) Prenatal Exposure to Antidepressant Medications and Neurodevelopmental Outcomes: A Systematic Review. Journal of Affective Disorders, 128, 1-9. http://dx.doi.org/10.1016/j.jad.2010.02.125

[45] Holmes, A., Murphy, D.L. and Crawley, J.N. (2002) Reduced Aggression in Mice Lacking the Serotonin Transporter. Psychopharmacology, 161, 160-067. http://dx.doi.org/10.1007/s00213-002-1024-3

[46] Holmes, A., Yang, R.J., Lesch, K.-P., Crawley, J.N. and Murphy, D.L. (2003) Mice Lacking the Serotonin Transporter Exhibit 5-HT ${ }_{1 \mathrm{~A}}$ Receptor-Mediated Abnormalities in Tests for Anxiety-Like Behavior. Neuropsychopharmacology, 28, 2077-2088. http://dx.doi.org/10.1038/sj.npp.1300266

[47] Lira, A., Zhou, M., Castanon, N., Ansorge, M.S., Gordon, J.A., Francic, J.H., Bradley-Moor, M., Lira, J., Underwood, M.D., Arango, V., Kung, H.F., Hofer, M.A., Hen, R. and Gingrich, J.A. (2003) Altered Depression-Related Behaviors and Functional Changes in the Dorsal Raphe Nucleus of Serotonin Transporter-Deficient Mice. Biological Psychiatry, 54, 960-971. http://dx.doi.org/10.1016/S0006-3223(03)00696-6

[48] Whitaker-Azmitia, P.M. (2005) Behavioral and Cellular Consequences of Increasing Serotonergic Activity during Brain Development: A Role in Autism? International Journal of Developmental Neuroscience, 23, 75-83. http://dx.doi.org/10.1016/j.ijdevneu.2004.07.022

[49] Simpson, K.L., Weaver, K.J., de Villers-Sidani, E., Lu, J.Y.-F., Cai, Z., Pang, Y., Rodriguez-Porcel, F., Paul, I.A., Merzenich, M. and Lin, R.C.S. (2011) Perinatal Antidepressant Exposure Alters Cortical Network Function in Rodents. Proceedings of the National Academy of Sciences of the United States of America, 108, 18465-18470. www.pnas.org/cgi/doi/10.1073/pnas.1109353108

[50] Kitahara, Y., Ohta, K., Hasuo, H., Shuto, T., Kuroiwa, M., Sotogaku, N., Togo, A., Nakamura, K.-I. and Nishi, A. (2016) Chronic Fluoxetine Induces the Enlargement of Performant Path-Granule Cell Synapses in the Mouse Dentate Gyrus. PLoS ONE, 11, e0147307. http://dx.doi.org/10.1371/journal.pone.0147307 